\title{
The Problem of Non-linearity: An Engineering Students' Misconception
}

\author{
Elena Trotskovsky and Nissim Sabag
}

\begin{abstract}
Linearization of non-linear physical processes is a standard approach for analyzing various non-linear systems. It is widely used in different engineering disciplines. It is known that school students are inclined to apply linear or proportional models in mathematical and physical problem solving. However, engineering students have difficulties with linearization and do not always apply the method correctly. A long pedagogical practice of more than 30 years in the field of electricity and electronics higher education have brought the authors to the assumption that the students have a misconception of non-linearity, which prevents them from understanding of the concept correctly.

Students' difficulties with linearization are expressed in the Analog Electronics course, where the students first encounter non-linear components - diodes. Electrical engineering students learn Analog Electronics after the Electricity and Electrical Circuits course, during which they mostly deal with linear interpretations of basic electrical components - resistors, capacitors and coils. At the very beginning of diode learning the students look for a simple linear dependency between current and voltage, like $\mathrm{Ohm}$ law. Afterwards, they misunderstand that they need to choose an appropriate linear model according to different circuit conditions, and to use it.
\end{abstract}

A qualitative research methodology was applied. 12 open interviews with the students were carried out. Two main problems were found: 1) part of the students do not perceive why different circuit conditions demand different linear models; 2) while solving the problem, some students cannot choose the correct model and determine the suitability of the results to the given conditions.

The study can help the engineering educators to be aware of students' misunderstanding of non - linearity and find pedagogical ways to overcome it.

Index Terms-Engineering model, linearization, misconception, non-linearity.

\section{INTRODUCTION}

Learning engineering is accompanied by the creation of misconceptions of basic science concepts. According to the classical approach to erroneous perceptions or misconceptions [1], relied on pedagogical research in the area of mathematics and science learning, students come to class with early theories based on their day-to-day life, that is, with intuitive perceptions. Systematic errors in thinking are the results of these perceptions [2]. One of the most popular definitions of misconception [3] suggests: "There are ideas derived from daily experience that students bring to their

Manuscript received October 31, 2018; revised April 1, 2019.

The authors are with the Department of Electrical and Electronics Engineering, Ort Braude College of Engineering, Karmiel, Israel (e-mail: elenatro@braude.ac.il,nsabag@braude.ac.il). learning experience and that contradict scientific understanding and [are] often resistant to change". Although students' misconceptions in science are widely investigated in pedagogical literature, the misunderstandings of different engineering concepts are less researched [4], [5].

In contrast with such science disciplines as physics, in engineering courses, the students usually learn concepts and ideas that are unrelated to their life experience, and which are absolutely new to the learners. In this case, students misconceptions can be based on primary erroneous perceptions of new knowledge. If the student does not grasp that his understanding is incorrect and uses it in his learning practice, i.e. in problem solving, the erroneous perception strengths, can turn to a misconception and entrenches in the thinking of the future engineer.

Linearization of non-linear physical processes is a standard approach to the analysis of various non-linear systems. It is widely used in different engineering disciplines - electricity and electronics, mechanics, control theory, engineering design and others. It is known that secondary school students have a tendency to apply linear or proportional models in mathematical and physical problem solving [6]. Therefore, the linearization, which is a very common and frequently used method, must be well understood by the students. However, engineering students have difficulties with it and do not always apply the method correctly. Thus, the authors of [7] claim that 95\% of engineering students taking the course of Control Theory, make the same mistakes in linearization methodology - they ignore the operating point of controller and apply the controller to the system without considering the operating point. [6] describes students' misunderstanding of the problem in the field of Electrical and Electronics engineering: the behavior the P-N diode. According to the authors, many students could not differentiate between the linear or resistive behavior of $\mathrm{N}-\mathrm{N}$ junction and non-linear behavior of $\mathrm{P}-\mathrm{N}$ junction or diode.

A long pedagogical practice of more than 30 years in the field of electricity and electronics higher education have brought the authors of the current article to the assumption that engineering students have a misconception of non-linearity, which prevents part of them from correctly understanding of the concept.

\section{THEORETICAL BACKGROUND}

Students' difficulties with linearization are expressed in the Analog Electronics course, where the students first encounter non-linear components, such as diodes and transistors. Electrical and Electronics (EE) engineering students learn 
Analog Electronics after the courses of Physics 2 and Electricity and Electrical Circuits, during which they mostly deal with linear interpretations, such as Ohm law and linear differential equations, described behavior of basic electrical components - resistors, capacitors and coils.

In contrast with these components, the $\mathrm{P}-\mathrm{N}$ junction diode behavior is non-linear. The current-voltage characteristic of a silicon diode is presented in Fig.1.

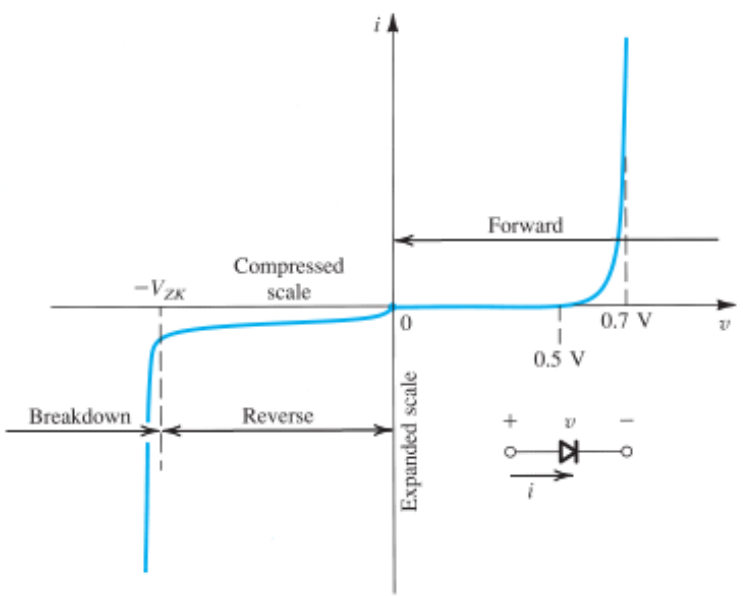

Fig. 1. The I-V characteristic of a silicon junction diode [8]

The mathematical model describes an exponential relationship between current I through a diode and voltage drop $\mathrm{V}$ on it, as follows:

$$
I=I_{S}\left(e^{V / V_{T}}-1\right)
$$

where $I_{S}, V_{T}$ are the constants at a given temperature.

In engineering practice, it is inconvenient to use a non-linear equation (1). The common approach is a linearization of the I-V characteristic and a usage of linear engineering models, which must supply reliable calculating results. Thus, for the diode one of the most popular models is constant-voltage drop model. The simplified current-voltage characteristic of a constant-voltage drop diode model is presented in Fig. 2.

According to the model, the diode can be presented as a power source with a constant voltage drop $V_{D}=0.7 \mathrm{~V}$, when it is forward- conducting, and as open switch with $I_{D}=0$, when it is reverse biasing.

There are additional models of a diode: the model of an ideal diode with zero voltage drop, $V_{D}=0$ in forward biasing area, and a small signal or piecewise model, where in forward-conducting area the diode is presented as a power source with a constant voltage drop $V_{D}=0.7 \mathrm{~V}$ connected in series with the resistor $r_{D}=\frac{d v_{D}}{d i_{D}}$. Graphical analysis and the usage of the I-V characteristic provides the highest accuracy of the results, but is not commonly used in engineering practice because it requires information about a specific diode, and it is difficult to apply it in complex electronic circuits.

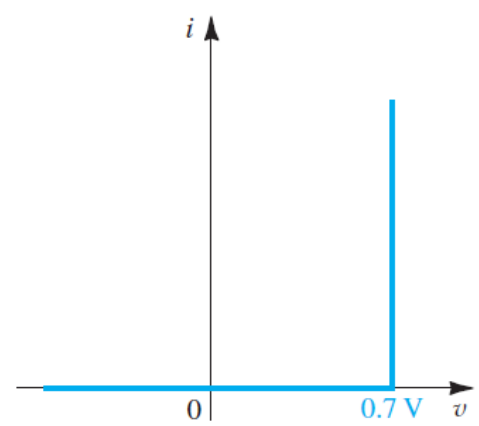

Fig. 2. The simplified current-voltage characteristic of a constant-voltage drop diode model [8, p.193].

The linearization process and the choice of an appropriate diode model in different circuits and different conditions seems to be very difficult for novice engineering students. The previous study [9] revealed that the students, solving problems using models, misunderstand a basic engineering goal: to get the results, which are maximally close to real life. This misconception might intertwine with the misconception of non-linearity. The current study aims to illuminate students' difficulties in understanding the basic concept of non-linearity.

\section{THE RESEARCH SETTING}

\section{A. The Method}

A qualitative research methodology was applied in the study. The qualitative approach is well-established in educational research [10], and frequently used to profoundly delve into different phenomena in educational processes.

\section{B. Research Aim}

The study investigates the EE undergraduate students' understanding of the non-linearity concept, based on their written solutions using different models of $\mathrm{P}-\mathrm{N}$ diode, and oral explanations of the solutions.

\section{The Participants}

The research was carried out in October 2017- January 2018. The participants of the study were EE students of a 14 weeks Analog Electronics course in an engineering college in Israel. The course was medium sized (about 50 students), and was taught by one lecturer and one tutor.

\section{The Activities}

The questionnaire included four simple problems that require the usage of an appropriate model of $\mathrm{P}-\mathrm{N}$ diode in different conditions. It was designed and applied in class after learning the diode subject during the course. The questionnaire is presented in the Appendix. The students answered the questionnaire during the lectures. After an examination of the students' answers, open interviews with 12 students who demonstrated misunderstandings of the non-linearity concept were carried out.

The students who participated in a semi-structured interviews were asked to explain their solution on the questionnaire problems, and the reasons for the erroneous choice of the solution.

The explanations given by students were analyzed and 
summarized.

\section{FINDINGS}

The misunderstanding of the non-linearity of the diode current-voltage curve was reflected in the students' explanation about the choice of an appropriate model in the solution of the questionnaire.

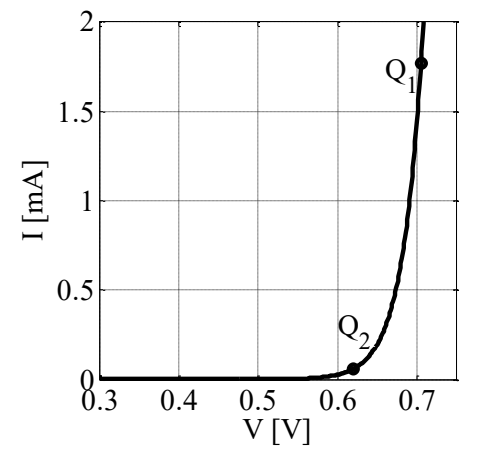

Fig. 3. Current-voltage characteristic of a diode.

By analyzing questions 3 and 4 in the Appendix, it can be seen that decreasing the resistance $\mathrm{R}$ moves the operating point to the upper part of the volt-ampere curve (Q1) (Fig. 3), where the constant voltage drop over the diode can be established as a constant value of approximately $0.7 \mathrm{~V}$. Increasing the resistance $\mathrm{R}$ moves the operating point to the lower part of the volt-ampere curve (Q2). In Q2 the characteristic is strongly non-linear and voltage drop is rapidly changing from point to point. Therefore, using the given current-voltage curve for problem solving in point Q2 is preferable. Applying a constant voltage drop diode model (voltage $\operatorname{drop} V_{D}=0.7 \mathrm{~V}$ ) at point $\mathrm{Q} 2$ provides less accurate results.

Six out of the 12 interviewees misunderstood the non-linear characteristic of a diode. They implemented the same constant voltage drop diode model on both operating points $(\mathrm{Q} 1, \mathrm{Q} 2)$. When interviewed, student $\mathrm{P}$ was asked to compare the results of the current calculation according to the I-V characteristic and the application of a constant voltage drop model of a diode. He answered:

P: Why do I need to choose an appropriate model? Why can't I use the same Ohm's law that I use, for example, for a resistor?

Three students applied the ideal diode model for problems 3 and 4. This model is not appropriate for these problems because the input voltage $V=1 V$ is low and the negligence of the voltage drop on the diode (about $0.6-0.7 \mathrm{~V}$ ) causes unreliable value of the current. One of them explained his choice in the following manner:

A: It was the simplest solution, therefore, I chose it.

When was asked about the reliability of the calculating results, he answered:

A: Is it important? I have never thought about it.

Two students explained the reason for the non-accuracy of the solution results by Ohm's law, namely, by the linear relationship between current and voltage:

$\mathrm{J}$ : The results are not accurate because we don't know the accurate value of diode resistance. If we know it precisely, we will be able to calculate the current with high accuracy.

$\mathrm{J}$. misunderstood that non-linearity of the I-V curve equals to the continuous change of the internal resistance of the diode from point to point, and it is impossible to know its value in each operating point.

Discussion

From the given explanations it can be seen that part of students misperceive the essence of non- linearity. EE students learn Analog Electronics after the Electricity and Electrical Circuits course, during which they mostly deal with linear interpretations, such as Ohm law, of basic electrical components - resistors, capacitors and coils. It can be seen that at the very beginning of non-linear components learning in the Analog Electronics course, the students look for a simple linear dependency between current and voltage, like Ohm law, on the devices. They seek the simple linear relationship between parameters of the non-linear device (diode), and do not understand why they need to apply different models of a diode in different conditions. This misconception can be illustrated by the findings described in [5], where the students sketched linear current-voltage characteristics of $\mathrm{P}-\mathrm{N}$ junction. It is in line with the finding described in [4, p.1597]: "The students seek to find the causes of phenomena under study, and seem to prefer simplistic, one-to-one casual relationships." Additional evidence of the difficulties in linearization methodology and the existence of the non-linearity misconception was given by the authors of [7] - students forget the operating point.

In the current study, similar as in the previous [9], the non-linearity misconception intervened with the misconception about a fundamental engineering principle: the calculating results must be reliable and close to real life results. Part of the students prefer using the simplest model of an ideal diode, although their results are far from being correct.

Dwelling on one concrete model and not using others can attest to poorly developed analytical skills among part of undergraduate students. The authors of [11] found that the differences between successful and unsuccessful problem solvers are the number of diverse representations they operate in the course of problem solution. Therefore, developing analytical skills by visualizing the linearization process, along with designing carefully-constructed educational simulations, as the authors of [5] suggest, and using different representations and models in lectures and tutorials can help students to overcome this problem and to cultivate proper science understanding of non- linearity.

The study can be useful for the engineering educators to be aware of students' misunderstanding of non-linearity and help them to find pedagogical ways to overcome it.

\section{APPENDIX - THE QUESTIONNAIRE}

Consider a circuit with a diode in Fig. 4.

Current-voltage characteristic of the diode is presented in Fig. 5.

In the solution of the problem, you can use:

1) ideal diode model $V_{D}=0 \mathrm{~V}$,

2) constant voltage drop $V_{D}=0.7 \mathrm{~V}$ model,

3) current-voltage curve 
1) Find the current in the circuit using:

- Ideal diode model

- Constant voltage drop diode model

- Current-voltage characteristic

2) Complete the following table based on the results of the previous question.

\begin{tabular}{|l|l|}
\hline Accuracy & Model \\
\hline Low & \\
\hline Middle & \\
\hline High & \\
\hline
\end{tabular}

3) R's resistance decreased to $400 \Omega$. What kind of diode model — (1), (2), or (3) — is the most suitable for solving the problem? Explain your choice and calculate the current through resistor $\mathrm{R}$.

4) R's resistance increased to $10 \mathrm{k} \Omega$. Which one of the above models is the most appropriate for calculating current and voltages in this case? Please explain your choice and calculate the current through resistor R.

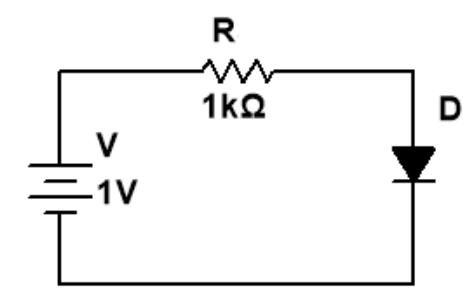

Fig. 4. The circuit with a diode.

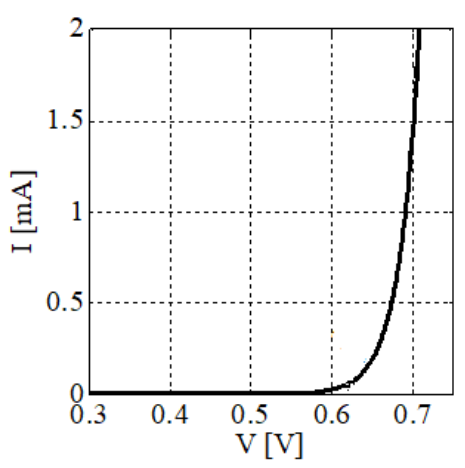

Fig. 5. Current-voltage characteristic of the diode.

\section{REFERENCES}

[1] L. B. Resnick, "Mathematics and science learning qualitative research: A new conception," Science, vol. 220, pp. 477-478, 1983.

[2] H. Radatz, "Students' errors in mathematical learning process: A survey," For the Learning of Mathematics, vol. 1, no. 1, pp. 16-20, 1980.
[3] J. Cromley and R. J. Mislevy, "Task templates based on misconception research (PADI technical report 6)," Menlo Park, CA: SRI International, 2005.

[4] D. Montfort, G. L. Herman, S. Brown, H. M. Matusovich, and R. A. Streveler, "Patterns of student conceptual understanding across engineering content areas," Int. J. of Eng. Educ., vol. 31, no. 6A, pp. 1587-1604, 2015.

[5] G. C. Adam, D. B. Harlow, S. M. Lord, and C.H. Kautz, "Conceptual understanding of P-N diode among undergraduate electrical engineering students," Int. J. of Eng. Educ., vol. 33, no. 1, pp. 261-271, 2017.

[6] D. Bock, W. V. Dooren, D. Janssen, and L. Verschaffel, "Improper use of linear reasoning: An in-depth study of the nature and the irresistibility of secondary school students' errors," Educ. Studies in Math., vol. 50, no. 3, pp. 311-334, 2002.

[7] J. Roubal, P. Husek, and J. Stecha, "Linearization: Students forget the operating point," IEEE Trans. on Educ., vol. 53, no. 3, pp. 413-418, 2010.

[8] A. S. Sedra and K. C. Smith, Microelectronic Circuits, 7th ed., Oxford University Press, NY, Oxford, 2015.

[9] E. Trotskovsky, N. Sabag, and S. Waks, "Students' achievements in solving problems using models and their misunderstanding of models in electronics - A case study," IEEE Trans. on Educ., vol. 58, no. 2, pp. 104-109, 2015.

[10] A. Cooley, "Qualitative research in education: The origins, debates, and politics of creating knowledge," Educ. Studies, vol. 49, no. 3, pp. $247-262,2013$

[11] G. M. Bodner and D. S. Domin, "Mental models: the role of representations in problem solving in chemistry," Univ. Chemistry Educ., vol. 4, no. 1, pp. 24-30, 2000.

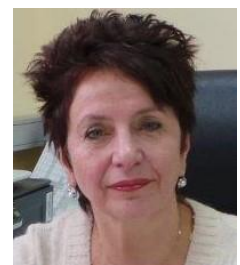

Elena Trotskovsky holds an MSc in EEE (1978) from Ufa Aviation Institute, Russia, an MSc, PhD (2009 and 2013 respectively) in technology and science education from the Technion, Israel Institute of Technology. She is a senior lecturer at the Department of Electronics \& Electrical Engineering, and in the past she was the head of Teaching and General Studies Unit, ORT Braude College, Karmiel, Israel. She received 8 prizes for being an outstanding faculty member. She has published 11 refereed papers in international journals, and 23 papers in refereed conference proceedings.

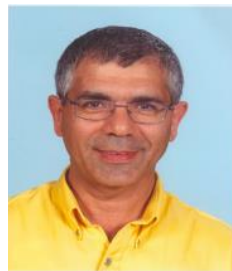

Nissim Sabag holds a BSc in EEE (1982), a BSc MSc, PhD (1995, 1998 and 2002 respectively), in Technology and Science Education from the Technion-Israel Institute of Technology. He is a senior lecturer and a head of the Department of Electronics \& Electrical Engineering, ORT Braude College, Karmiel, Israel. He was: Head of academic administration, Chair of the Collegial Committee of Academic Affairs, Member of the higher academic council and many other academic positions at the ORT Braude College. He was the head of a project involving eight high schools for improving learning and teaching of electronics for this he received a Certificate of recognition for enhancing the teaching level of electronics from the Ministry of Education. He also received 14 prizes for being an outstanding faculty member. He has published 15 refereed papers in international journals, 2 chapters in refereed paper books and 18 papers in refereed conference proceedings. 